\title{
Distribution and attachment characteristics of Sida crystallina (O.F. Müller, 1776) in lentic freshwater ecosystems of South Korea
}

\author{
Jong-Yun Choi ${ }^{1 *}$, Kwang-Seuk Jeong ${ }^{2,3}$, Seong-Ki Kim ${ }^{4}$, Se-Hwan Son ${ }^{1}$ and Gea-Jae Joo ${ }^{2}$
}

\begin{abstract}
Background: Macrophytes are commonly utilised as habitat by epiphytic species; thus, complex macrophyte structures can support high diversities and abundances of epiphytic species. We tested the hypothesis that the presence of aquatic macrophytes is an important factor determining Sida crystallina (O.F. Müller, 1776) distribution.

Results: An ecological survey was conducted in 147 lentic freshwater bodies. S. crystallina was frequently observed, and its density was strongly associated with macrophyte abundance. S. crystallina was found on emergent plant species such as Phragmites australis and Paspalum distichum, attached to the stem surfaces by adhesive substances secreted by the nuchal organ. Thus, S. crystallina was more strongly attached to macrophytes than to other epiphytic cladoceran species. We found higher densities of S. crystallina in filtered water with increased macrophyte shaking effort (i.e. 10, 20, 40, or 80 times). S. crystallina attachment was not related to fish predation. Stable isotope analysis showed that $\mathrm{S}$. crystallina utilises epiphytic organic matter (EOM) on macrophytes as a food source.
\end{abstract}

Conclusions: Consequently, S. crystallina seems to have a strong association with species-specific macrophyte biomass than with other cladoceran species, which may contribute to this species' predominance in various freshwater ecosystems where macrophytes are abundant.

Keywords: Sida crystallina, Aquatic macrophytes, Attachment characteristics, Stable isotope analysis, Lentic freshwater ecosystems

\section{Background}

Aquatic macrophytes commonly occur in shallow aquatic ecosystems and can have dramatic effects on their physical structure (O'Hare et al. 2006; Smokorowski and Pratt 2007). Aquatic macrophytes give rise to heterogeneous spaces with varying degrees of structural complexity (Denny 1994; Findlay and Bourdages 2000). Some studies have suggested that vegetated beds with high structural heterogeneity provide small animals with refuges from predators and suitable spawning and foraging substrates, mediating trophic interactions among diverse organisms (Vieira et al. 2007; Thomaz et al. 2008). The effectiveness

\footnotetext{
* Correspondence: jyc311@nie.re.kr

${ }^{1}$ National Institute of Ecology, Seo-Cheon Gun, Chungcheongnam province 325-813, South Korea

Full list of author information is available at the end of the article
}

of macrophytes as a refuges and/or habitat varies with their life form, density, and species (see review in Burks et al. 2002). In particular, macrophyte morphological characteristics have a significant bearing upon the availability of small animals as a food source, mediated via detritus trapping (Rooke 1984) and the growth of periphytic algae (Cattaneo et al. 1998). Thus, the presence of aquatic macrophytes facilitates increased abundance and diversity in aquatic animal communities.

Among the many animals utilising macrophyte habitats, freshwater cladocerans are well known to exploit macrophytes as habitats and/or refuges (Kuczyńska-Kippen and Nagengast 2006; Choi et al. 2014a). The majority of studies that have focused on the interactions between macrophytes and cladocerans have considered the influence of macrophytes on pelagic cladoceran species (Jeppesen et al. 
1998; Meerhoff et al. 2007). These studies argued that aquatic macrophytes are capable of providing suitable habitats for mainly pelagic cladocerans. However, pelagic species are continuously exposed to predators such as fish due to their frequent movement; thus, it would be relatively difficult for such pelagic species to develop higher abundances in freshwater ecosystems. In comparison with other aquatic systems, shallow wetlands are characterised by abundant aquatic macrophytes, and this abundance of habitat tends to attract more cladoceran species. These are known as epiphytic cladocerans (i.e. plant-attached species; Castilho-Noll et al. 2010; Gyllström et al. 2005; Kuczyńska-Kippen and Nagengast 2006) and are strongly affected by the abundance, morphology, and arrangement of plant species (Choi et al. 2014b). Unfortunately, epiphytic cladoceran distribution patterns and modes of macrophyte utilisation are still unclear, and their abundances are usually underestimated.

Sida crystallina (Cladocera: Sididae, O.F. Müller 1776) is a typical epiphytic cladoceran species occurring in temperate and tropical waters. They attach to aquatic macrophytes by means of maxillary glands and thus filter feed in fixed positions (Fairchild 1981). Compared with other cladoceran species, S. crystallina occurs at relatively high water temperatures (approximately 21 to $22{ }^{\circ} \mathrm{C}$; Kotov and Boikova 1998) and is prevalent in temperate zones during summer (Balayla and Moss 2003). They are found in most shallow freshwater ecosystems in South Korea during summer (Choi et al. 2014c). Unfortunately, although the overall distribution of the species has been reported (Downing and Peters 1980; Lauridsen et al. 1996), its distribution patterns, attachment characteristics, and feeding habits have been insufficiently studied.

In this study, we investigated the distribution patterns of S. crystallina in lentic freshwater ecosystems in South Korea. We hypothesised that S. crystallina may prefer shallow wetland microhabitats in which macrophytes dominate and may utilise epiphytic algae growing on macrophyte stands as their food source. To test these hypotheses, we investigated (i) the influence of diverse physicochemical parameters and macrophytes on $S$. crystallina distribution and (ii) the nature of attachment of S. crystallina in relation to fish predation and food availability. We surveyed 147 lentic ecosystems in South Korea and recorded physicochemical parameters of water, macrophyte occurrence, and S. crystallina densities.

\section{Methods}

\section{Study sites}

South Korea is located in East Asia and has a temperate climate. Four distinct seasons lead to the dynamic succession of biological communities in the freshwater ecosystems of South Korea. Annual mean rainfall is ca. $1150 \mathrm{~mm}$, more than $60 \%$ of which occurs from June to early September (Choi et al. 2011; Jeong et al. 2007). Our study sites were located in south-eastern South Korea, along the middle and lower reaches of the Nakdong River. Historically, there were numerous riverine wetlands in this river basin (Son and Jeon 2002); however, large areas of wetland have vanished due to the expansion of human society (Burkett and Kusler 2000). The dominant land cover surrounding reservoirs is agricultural, and nonpoint source pollution continuously influences the study sites (Korean Ministry of Environment 2006).

We investigated 147 lentic freshwater ecosystems in the river basin (wetlands, ponds, and reservoirs; see Fig. 1). The wetlands and shallow lakes are dominated by various macrophyte species; however, the development and growth of macrophytes is inhibited in reservoirs and some lakes due to their impermeable floors. In addition, some wetlands support only a few plant species because of high water levels and low nutrient concentrations. Therefore, the study sites encompassed a wide range of microhabitat characteristics (i.e. different types of lentic systems and different patterns in their constituent plant communities).

\section{Monitoring strategy}

The target species $S$. crystallina is known to prefer relatively high water temperatures (approximately 21 to $22{ }^{\circ} \mathrm{C}$; Kotov and Boikova 1998) and is prevalent in temperate zones during summer (Balayla and Moss 2003). Based on this information, we monitored study sites in summer (June to July 2012). At each site, three sampling points were established in the littoral zone.

Physicochemical parameters were measured and $S$. crystalline collected at each sampling point. Water temperature, dissolved oxygen, conductivity, $\mathrm{pH}$, chlorophyll a, and turbidity were measured at each site. Water samples were collected at a depth of $0.5 \mathrm{~m}$. We used a DO meter (YSI DO meter; Model 58, YSI Research Inc., OH, USA) to measure water temperature and dissolved oxygen. Conductivity and $\mathrm{pH}$ were measured using a conductivity meter (YSI Model 152; Yellow Springs Instruments, Yellow Springs, $\mathrm{OH}, \mathrm{USA}$ ) and $\mathrm{pH}$ meter (Orion Model 250A; Orion Research Inc., Boston, MA, USA). Turbidity and chlorophyll a concentration were measured in the laboratory. Turbidity was measured using a turbidimeter (Model 100B; Scientific Inc., Ft. Myers, FL, USA). The water samples were filtered through mixed cellulose ester (MCE) membrane filters (Advantech; Model No., A045A047A; pore size, $0.45 \mu \mathrm{m}$ ), and chlorophyll a concentration was ascertained based on the methodology of Wetzel and Likens (2000).

At each sampling point, we took an additional $10 \mathrm{~L}$ of water for zooplankton collection from the surface layer (to a depth of $0.5 \mathrm{~m}$ ), using a 10-L column sampler. This water was filtered through a plankton net $(68-\mu \mathrm{m}$ mesh size), and the filtrate was preserved in sugar formalin 


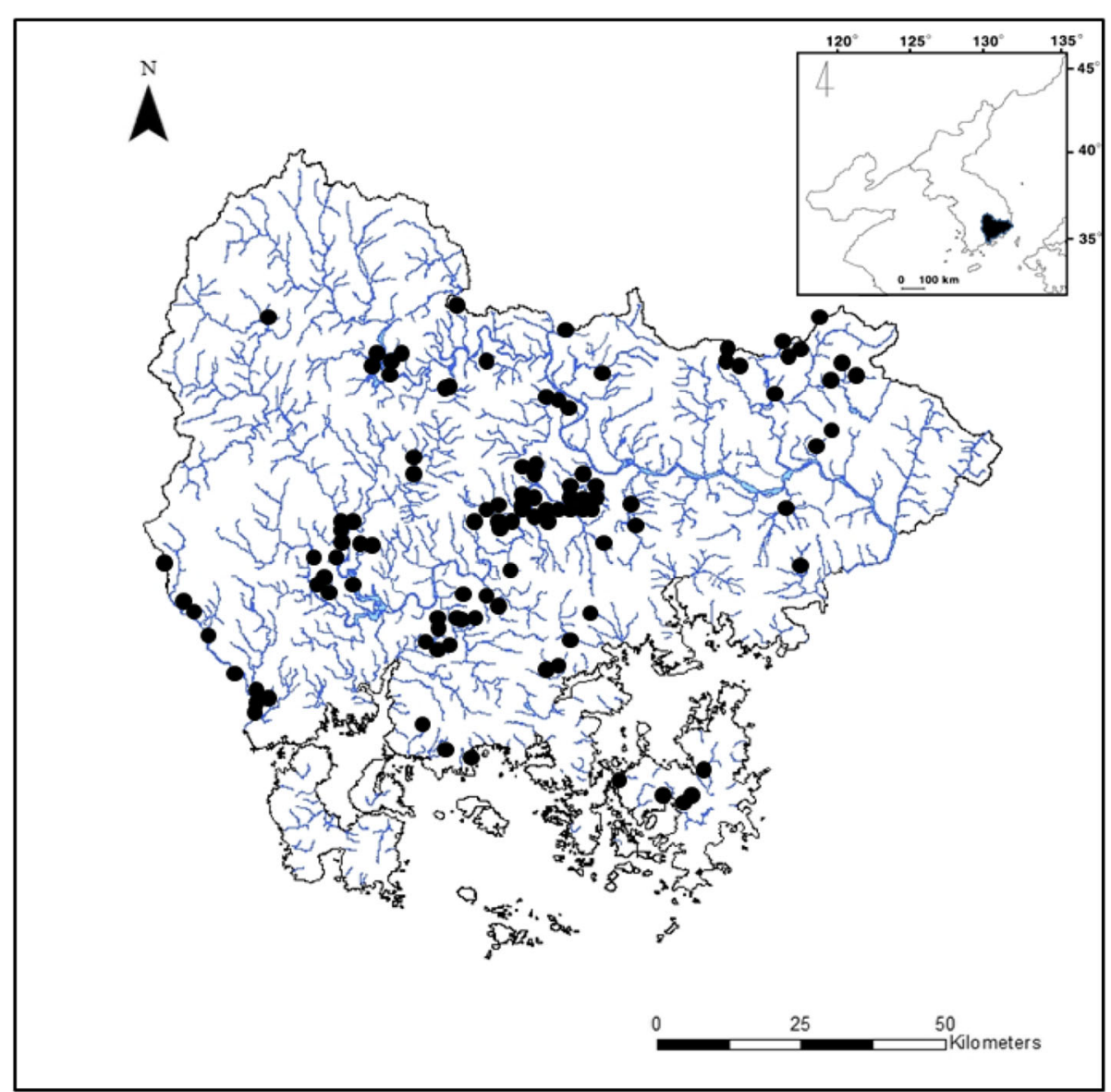

Fig. 1 Map of the study area in south-eastern South Korea. The study sites are indicated as solid circles. The small map in the upper right corner shows the Korean Peninsula

(final concentration $4 \%$ in the form of aldehyde). $S$. crystallina and other zooplankton species were identified and counted using a microscope (ZEISS, Model Axioskop 40; $\times 200$ magnification) using the classification key of Mizuno and Takahashi (1991).

To investigate attachment characteristics of S. crystallina, we additionally collected $S$. crystallina from stems and leaves of macrophytes at six sites where high abundances of S. crystallina were observed. We established five quadrats $(0.5 \mathrm{~m} \times 0.5 \mathrm{~m})$ along the littoral zone at each of these sites and counted all S. crystallina within each quadrat. We did not include emergent organs of macrophytes above the water surface (i.e. stalks and flowers) because S. crystallina inhabit underwater environments. The submerged parts were handled carefully to prevent $S$. crystallina from accidentally detaching. S. crystallina were kept alive using filtered wetland water. Small animals including zooplankton were removed from $2 \mathrm{~L}$ of water using a plankton net ( $32 \mu \mathrm{m}$ mesh size), and the filtered water was stored in 5-L tanks. This water was used as temporary storage for epiphytic species including S. crystallina. Collected macrophytes were shaken in the tank to detach S. crystallina (for the detaching process, see Sakuma et al. 2002). S. crystallina on the plants were detached by shaking 10 , 20,40 , and 80 times. After collection of S. crystallina at the study sites, macrophyte samples were carried to the laboratory and dried at $60{ }^{\circ} \mathrm{C}$ for 2 days. Epiphytic species, including S. crystallina, were filtered from the water using a $68 \mu \mathrm{m}$ mesh net and immediately fixed with sugar formalin (final concentration $4 \%$ in the form of aldehyde). We counted numbers of $S$. crystallina using a microscope (ZEISS, Model Axioskop 40; ×200 magnification). Densities of $S$. crystallina attached to plants were expressed as number of individuals per gramme dry weight of macrophyte (ind. $\mathrm{g}^{-1} \mathrm{dw}$ ).

\section{Microcosm experiment}

To understand how the attachment characteristics of $S$. crystallina influence fish predation, we conducted additional microcosm experiments. Approximately 200 S. crystallina adult individuals with similar life-history traits (body size and condition of clutch) were selected. These S. crystallina individuals were acclimatised for approximately $48 \mathrm{~h}$ in a stock culture environment 
(Elendt M4 medium; Elendt 1990). To simulate the fish predation, we used fish chemical cues (De Meester and Cousyn 1997) in this microcosm experiment. A total of five fish species were considered, Micropterus salmoides (Lacepéde 1802), Lepomis macrochirus (Rafinesque 1819), Pseudorasbora parva (Temminck and Schlegel 1846), Rhinogobius brunneus (Temminck and Schlegel 1845), and Misgurnus anguillicaudatus (Cantor 1842). We collected samples of these fish at the study sites where we obtained S. crystallina using a $7 \mathrm{~mm} \times 7 \mathrm{~mm}$ cast net and a $5 \mathrm{~mm} \times 5 \mathrm{~mm}$ scoop net. To obtain fish chemical cues from the collected fish, we allocated each fish species to one of five tanks, and five individuals of each fish species were acclimatised in each tank for $24 \mathrm{~h}$ (tanks filled with $10 \mathrm{~L}$ Elendt M4 medium).

The experiment was designed as follows: a total of six groups-control (no predation) and five experimental groups by using each of the fish species. First, we prepared 60 500-mL beakers (10 beakers per experimental group) and filled each with $300 \mathrm{~mL}$ of clear M4 medium. We put five S. crystallina individuals in each beaker and allowed them to acclimatise to the new environment for $30 \mathrm{~min}$. During the acclimatisation period, we prepared the fish chemical cues used in the experiment: the fish-exposed M4 medium was filtered using a $30 \mu \mathrm{m}$ mesh net (used only in this experiment and not used for field plankton collection) to remove particulate matter. Before introducing the resulting fish chemical cues to the experimental beakers, we very carefully marked the position of each $S$. crystallina individual on the outer surface of every beaker. Then, we injected $200 \mathrm{~mL}$ of fish chemical cue into each beaker. For the control group, unexposed, clear M4 medium was added. The S. crystallina individuals were allowed to respond to the changed environment for $30 \mathrm{~min}$, and then, we investigated the number of moved individuals.

\section{Data analysis}

We used two-way ANOVA $(\alpha=0.05)$ to analyse how the density of $S$. crystallina varied with shaking procedure (i.e. 10, 20, 40, and 80 times) and collection site. Differences in S. crystallina movement among fish predation treatments were analysed statistically using one-way ANOVA. Furthermore, the relationships between $S$. crystallina density and environmental variables were tested using stepwise multiple regression. All statistical analyses, including stepwise multiple regression and ANOVA, were conducted using the statistical package SPSS for Windows ver. 14.

\section{Stable isotope analysis}

Stable isotope analysis was conducted to identify the food sources of S. crystallina. Particulate organic matter (POM), epiphytic organic matter (EOM), and S. crystallina individuals were sampled at six different sites where $S$. crystallina was abundant. To process the POM samples, any small animals were first removed using a plankton net (32 $\mu \mathrm{m}$ mesh size), and then, the water samples were filtered through GF/F glass-fibre (pre-combusted at $500{ }^{\circ} \mathrm{C}$ for $2 \mathrm{~h}$ ). The surfaces of submerged parts of macrophytes from each study point were gently brushed in a tank filled with distilled water, in order to obtain the EOM. Similar to the processing of POM, micro- and macroinvertebrates were removed using the plankton net ( $32 \mu \mathrm{m}$ mesh size). $S$. crystallina individuals were isolated using a micropipette.

$\mathrm{POM}$ and EOM samples were treated with $1 \mathrm{~N} \mathrm{HCl}$ to remove inorganic carbon and rinsed with distilled water to remove the acid. S. crystallina samples were not acidified to remove inorganic carbon, because acidification affects nitrogen values (Pinnegar and Polunin, 1999). All samples were freeze-dried and homogenised with a mortar and pestle, and the powdered samples were kept frozen $\left(-70{ }^{\circ} \mathrm{C}\right)$ until analysis. Carbon and nitrogen isotope ratios were determined using continuous-flow isotope mass spectrometry. Dried samples (ca. $1 \mathrm{mg}$ for S. crystallina samples and $1.5 \mathrm{mg}$ for POM and EOM) were combusted in an elemental analyser (Euro EA 3000 Elemental Analyzer, Eurovector SPA., Milano, Italy), and the resultant gas $\left(\mathrm{CO}_{2}\right.$ and $\left.\mathrm{N}_{2}\right)$ was introduced to an isotope ratio mass spectrometer (CF-IRMS, IsoPrime) in a continuous flow using a helium carrier. Data were expressed as the relative concentration (\%) difference between sample and conventional standards of Pee Dee Belemnite carbonate (PDB) for carbon and atmospheric $\mathrm{N}_{2}$ for nitrogen according to the following equation:

$$
\delta X(\%)=\left[\left(R_{\text {sample }} / R_{\text {standard }}\right)-1\right] \times 1000
$$

where $X$ is ${ }^{13} \mathrm{C}$ or ${ }^{15} \mathrm{~N}$ and $R$ is the ${ }^{13} \mathrm{C}:{ }^{12} \mathrm{C}$ or ${ }^{15} \mathrm{~N}:{ }^{14} \mathrm{~N}$ ratio. A secondary standard (Peptone) of known relation to the international standard was used as a reference material. Standard deviations of $\delta^{13} \mathrm{C}$ and $\delta^{15} \mathrm{~N}$ for analyses with 20 replicates of Peptone standard were \pm 0.1 and $\pm 0.2(\%)$, respectively.

To determine which of the two food sources (POM and EOM) was assimilated more readily by S. crystallina, we used two-source isotope mixing models. The carbon isotope values of POM and EOM significantly differed among sites (see 'Results'). The model was defined as:

$$
\begin{aligned}
\delta^{15} \mathrm{C}_{M}= & f_{X}\left(\delta^{13} \mathrm{C}_{X}+\Delta^{13} \mathrm{~N}\right) \\
& +f_{Y}\left(\delta^{13} \mathrm{C}_{Y}+\Delta^{13} \mathrm{C}\right) ; 1 \\
= & f_{X}+f_{Y}
\end{aligned}
$$

where $X, Y$ and $M$ represent the two food sources and a mixture of the two, respectively; $f$ represents the proportion of $\mathrm{N}$ from each food source in the consumer's diet; and ${ }^{15} \mathrm{C}$ is the assumed trophic fractionation (i.e. the change in $\delta^{15} \mathrm{C}$ over one trophic step from prey to predator; Phillips and Gregg 2001). Trophic fractionation was 
assumed to be constant at either 3.4 or $2.4 \%$ (Minagawa and Wada 1984).

\section{Results}

Physicochemical parameters, macrophytes, and zooplankton

There were few differences in physicochemical characteristics of water among the study sites (Table 1). Although some study sites had exceptionally high or low values, the coefficients of variation (CV; standard deviation/mean $\times$ $100 \%)$ were lower than $100 \%$. Conductivity had the highest $\mathrm{CV}$, but this was only approximately $66.9 \%$.

Macrophyte species composition and dry weight differed among study sites. Paspalum distichum L. dominated most of the study sites; a total of 10 species of macrophyte were found (Phragmites australis Trin. (Cav.), P. distichum, Zizania latifolia Griseb., Scirpus tabernaemontani Gmel., Spirodela polyrhiza L., Salvinia natans L., Trapa japonica Flerov., Ceratophyllum demersum L., Hydrilla verticillata (L.F.) Royle, and Nymphoides indica (L.) Kuntze).

A total of 122 species of zooplankton were identified (86 rotifers, 27 cladocerans, and 9 copepods). The highest abundance of zooplankton was 4135 ind. $\mathrm{L}^{-1}$, followed by 3736 ind. $\mathrm{L}^{-1}$. Lecane hamata (Stokes 1897), Polyarthra vulgaris (Carlin 1943), Chydorus sphaericus (O.F. Müller 1785), and Diaphanosoma brachyurum (Lievin 1848) were recorded frequently.

S. crystallina was observed at 81 out of 147 sites. From the observation, S. crystallina was mostly found in shallow wetlands where macrophytes were present. Stepwise multiple regression showed that density and distribution of S. crystallina were clearly related to macrophyte biomass (d.f. for regression, residuals, and total $=2,143,146$, respectively; $F=94.32, P=0.001$, see Table 2 for independent variables). In addition, $S$. crystallina density was related to water depth and chlorophyll a concentration. However, other environmental parameters did not have significant influence on S. crystallina distribution or abundance.

Table 1 Mean macrophyte dry weights and physicochemical parameters measured at the study sites

\begin{tabular}{llllcc}
\hline Variable & Units & Max & Min & Mean $\pm \mathrm{SD}$ & $\mathrm{CV}(\%)$ \\
\hline Macrophyte biomass & $\mathrm{gdw}$ & 114.1 & 0 & $42.8 \pm 23.1$ & 68.4 \\
Water depth & $\mathrm{m}$ & 231 & 14 & $78.4 \pm 40.6$ & 51.7 \\
Water temperature & ${ }^{\circ} \mathrm{C}$ & 27.1 & 22.5 & $25.6 \pm 2.5$ & 11.2 \\
Dissolved oxygen & $\%$ & 217.2 & 21.6 & $87.9 \pm 34.2$ & 38.2 \\
Conductivity & $\mathrm{MS} \mathrm{cm}^{-1}$ & 746.7 & 83.6 & $187.8 \pm 125.6$ & 66.9 \\
$\mathrm{pH}$ & - & 8.8 & 6.3 & $7.8 \pm 0.6$ & 9.2 \\
Chlorophyll a & $\mathrm{Mg} \mathrm{L}^{-1}$ & 42.8 & 2.1 & $25.8 \pm 9.0$ & 35.2 \\
Turbidity & $\mathrm{NTU}$ & 24.0 & 1.33 & $9.4 \pm 6.0$ & 64.5 \\
Total nitrogen & $\mathrm{mg} \mathrm{L}^{-1}$ & 13.2 & 1.4 & $7.3 \pm 2.6$ & 25.4 \\
Total phosphorous & $\mathrm{mg} \mathrm{L}^{-1}$ & 123.2 & 23.6 & $76.7 \pm 32.5$ & 36.7 \\
\hline
\end{tabular}

Table 2 Summary of stepwise multiple regression between Sida crystallina abundance (response variable) and physicochemical parameters (explanatory variables)

\begin{tabular}{lllll}
\hline Response variable & Explanatory variables & \multicolumn{1}{l}{$B_{j}$} & \multicolumn{1}{l}{$l$} & $P$ \\
\hline Sida crystallina & Constant & 27.201 & -2.488 & 0.014 \\
& Macrophyte biomass $(\mathrm{g})$ & 2.469 & 12.287 & 0.000 \\
& Water depth $(\mathrm{mm})$ & 0.748 & 3.735 & 0.005 \\
& TP $\left(\mathrm{mg} \mathrm{L}^{-1}\right)$ & -1.794 & -2.185 & 0.031
\end{tabular}

Data were transformed prior to analysis using either the arcsine-square root (proportion of agricultural land) or log (all other variables) transformation

Interestingly, S. crystallina was frequently observed in sites where emergent plants such as $P$. australis and $P$. distichum dominated (Fig. 2). In particular, sites dominated by $P$. distichum supported higher densities of $S$. crystallina. By contrast, $S$. crystallina densities were low in sites where free-floating (S. natans), floating-leaved (T. Japonica), and submerged (C. demersum) macrophyte species dominated.

\section{Attachment characteristics of S. crystallina}

Numbers of $S$. crystallina detached from macrophytes differed with shaking effort at each site (Fig. 3). Two-way ANOVA revealed that $S$. crystallina counts were significantly affected by both shaking effort $(10,20,40$, or 80 times; d.f. $=3, F=265.98, P<0.05$ ) and sites (between total 6 sites; d.f. $=5, F=101.43, P<0.05)$. S. crystallina counts were proportional to the shaking effort, but the increase in counts tailed off as the efforts increased. This phenomenon was observed at all six study sites.

Interestingly, S. crystallina attachment was not affected by simulated fish predation (one-way ANOVA, d.f. $=5, F$ $=0.236, P=0.945$; Fig. 4). We counted the number of moved individuals of $S$. crystallina following exposure to fish chemical cues, but almost no individuals moved in any experimental group, including the control.

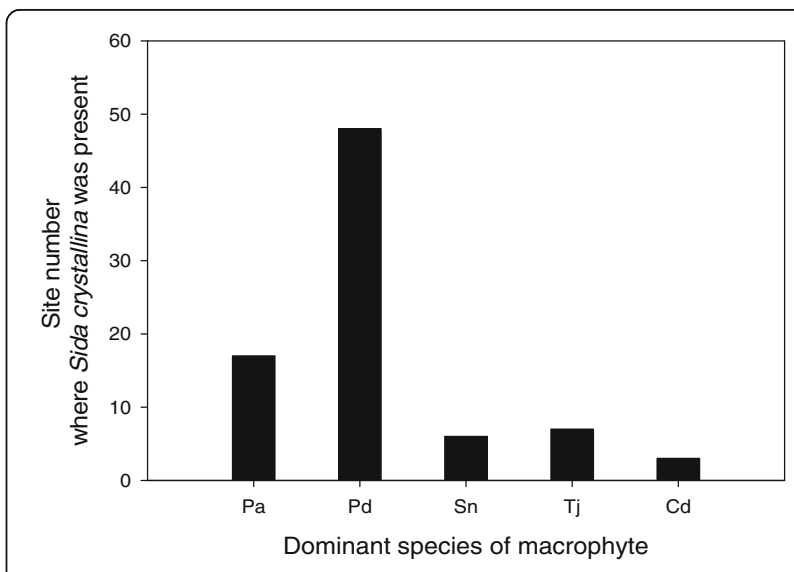

Fig. 2 Number of sites where S. crystallina was present classed by dominant species of macrophyte. Pa Phragmites australis Trin. (Cav.), Pd Paspalum distichum L., Sn Salvinia natans L., Tj Trapa japonica Flerov., Cd Ceratophyllum demersum L 


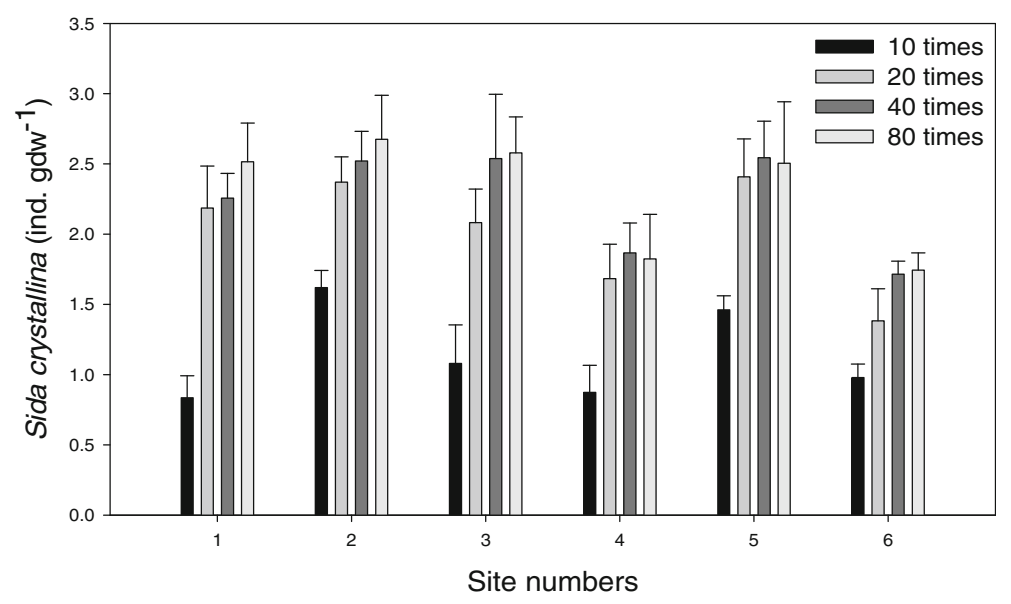

Fig. 3 Numbers of Sida crystallina detached from macrophyte stands based on the shaking effort (10, 20, 40, and 80 times) at each study sites

Figure 5 shows the organ used by $S$. crystallina for attachment. They attached to substrata using adhesive anchors that are connected to the cuticle by anchor threads.

\section{S. crystallina food sources}

The results of stable isotope analysis indicated potential food sources of S. crystallina. S. crystallina $\delta^{13} \mathrm{C}$ values indicated a bias in the composition of their food (between SPOM and EPOM) and reflected differences in the $\delta^{13} \mathrm{C}$ values of SPOM and EPOM (Fig. 6). At all sites, $S$. crystallina was more dependent on EPOM on macrophyte surfaces than SPOM. Although $\delta^{13} \mathrm{C}$ and $\delta^{15} \mathrm{~N}$ values of S. crystallina and EPOM differed among sites, a common relationship between the grazer and its diet could be assumed for all sites (a fractionation coefficient of $1 \%$ was used per trophic step for carbon isotopes

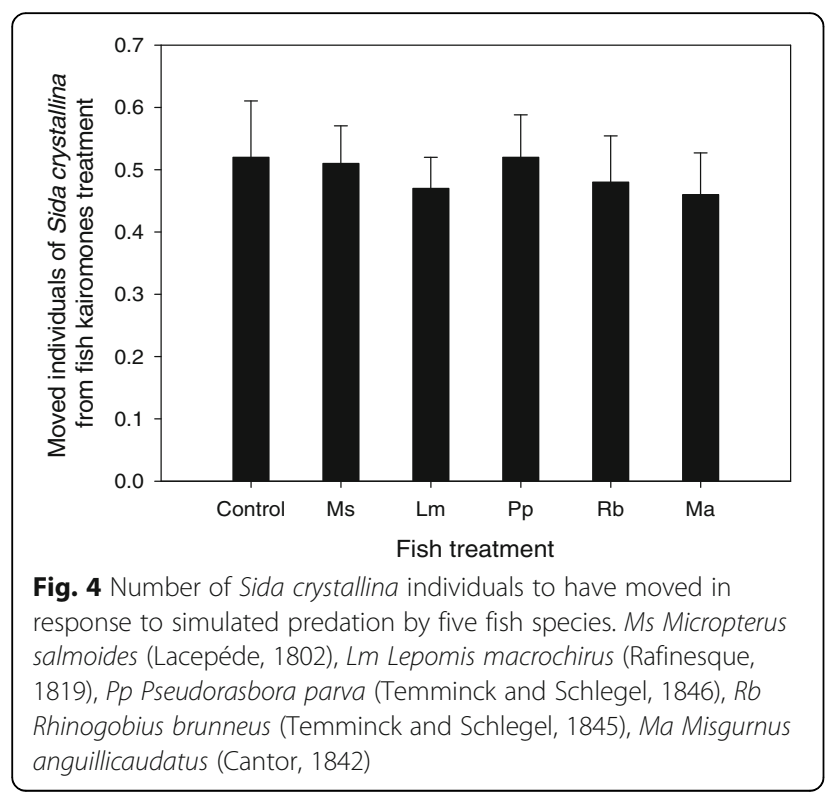

and 2 3\% per trophic step for nitrogen isotopes). Moreover, when the contributions of the two potential food sources to S. crystallina diet were calculated from isotope analyses, the contribution of EPOM (average, $83 \%$ ) was higher than that of SPOM (average, $17 \%$ ), according to the two-source mixing model.

\section{Discussion}

In this study, S. crystallina distribution showed a strong relationship with macrophyte biomass. Among cladoceran species, $S$. crystallina is well known to have an epiphytic character and mainly attaches to stem and leaf surfaces of

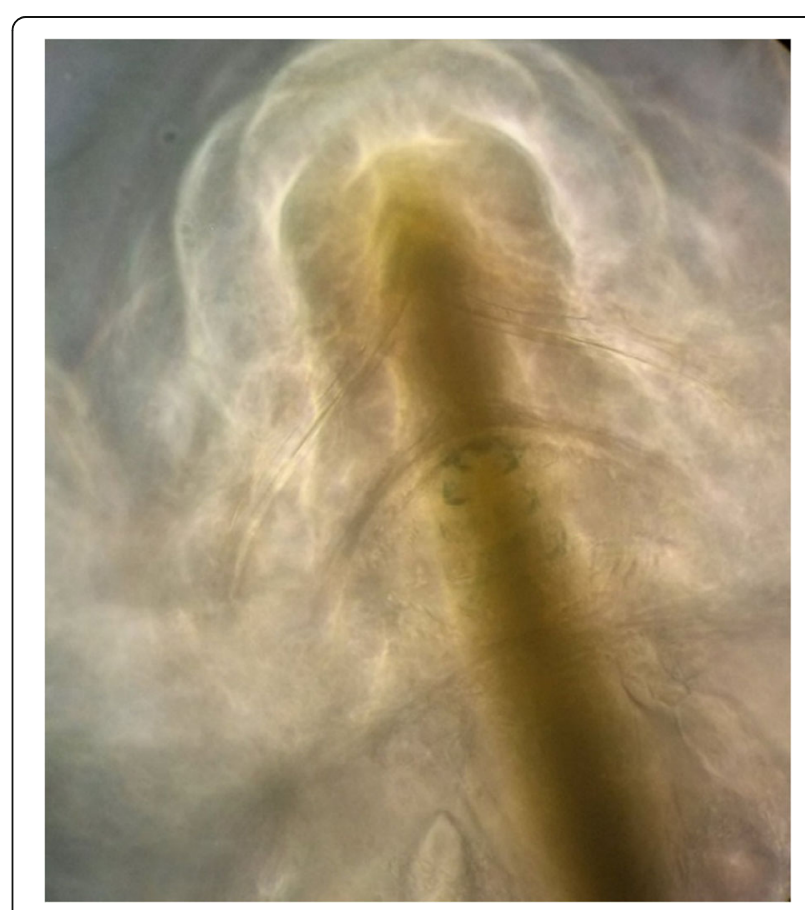

Fig. 5 Adhesive anchors of Sida crystallina 


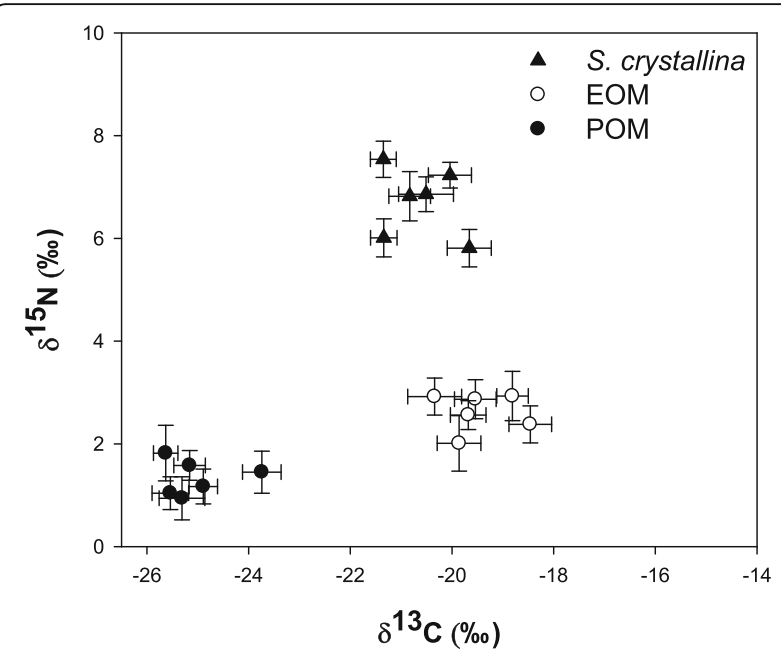

Fig. 6 Carbon and nitrogen isotope plots of POM, EOM, and Sida crystallina from each site. Each symbol represents the sample mean value

macrophytes. Thus, S. crystallina was not frequently observed in ecosystems where macrophytes were absent or not abundant. We found distribution patterns of $S$. crystallina varied with dominant macrophyte species. Moss et al. (1998) suggested that some epiphytic zooplankton species could attain high biomasses in free-floating and floating-leaved macrophyte beds. However, macrophyte species occupy limited space in the water (mostly at the water surface) and are mainly utilised as habitat by small species (i.e. rotifers; Choi et al. 2014c). Although submerged macrophytes make a large contribution to aquatic habitat complexity, the leaves and stems of submerged macrophytes are more easily agitated by wind and water currents than those of other plant species (Vermaat et al. 2000). As a result, they are less suitable for the attachment of epiphytic species. Some reports suggest that submerged macrophytes are mainly used by pelagic zooplankton, such as daphnids, as daytime refuges (Lauridsen and Lodge 1996; Burks et al. 2002). In contrast, emergent macrophyte species are tightly fixed in place and thus are suitable for attachment of large epiphytic species such as S. crystallina. Although emergent macrophytes are known to have simpler structure than other aquatic plant species (Choi et al. 2014b), it seems emergent plants are important as habitat for S. crystallina. In particular, S. crystallina was more abundant in ecosystems where $P$. distichum dominated than those dominated by other emergent macrophyte species (e.g. P. australis). We suggest that $S$. crystallina prefers $P$. distichum because it has a more complex structure (more diversified arrangement of stems and leaves) than $P$. australis. In addition, S. crystallina distribution was related to water depth and total phosphorus. Deeper water may increase the volume of water available to be occupied by macrophytes and thus support greater densities of $S$. crystallina. In addition, S. crystallina mostly occurred in aquatic environments where nutrient levels were relatively low. In such wetland, macrophytes are thought to make a large contribution to nutrient removal and improve water quality (Sooknah and Wilkie 2004). Thus, the positive relationship between $S$. crystallina and macrophyte biomass can explain the negative relationship with total phosphorus. However, further investigation is needed to better understand the relationships between S. crystallina and nutrient status.

From the results of an additional experiment on the interactions between S. crystallina and macrophytes, we found densities of $S$. crystallina on macrophyte varied with shaking effort $(10,20,40$, or 80 times) in filtered wetland water. We collected more $S$. crystallina individual as the number of shakes, suggesting that $S$. crystallina was strongly attached to the macrophytes. Similarly, Sakuma et al. (2002) compared densities of some epiphytic rotifer and cladoceran species on plants after shaking for different numbers of times and found large numbers of Lecane and Collotheca remained on plants even after shaking 50 times. However, numbers of the epiphytic cladoceran genus Alona did not vary with shaking effort. Some crustaceans, such as conchostracans or cladocerans, have nuchal organs named maxillary glands, which secrete excreta (Thorp and Covich 2001) that are used to attach to substrate surfaces. In particular, S. crystallina has well developed nuchal organs, allowing it to firmly attach to leaf and stem surfaces of macrophytes. Therefore, we considered that this strong attachment of $S$. crystallina to macrophytes caused the differences in observed densities with shaking effort. Moreover, S. crystallina populations had statistically different demographic structures among sites.

Attachment of S. crystallina was not affected by fish predation. Pelagic species such as daphnids actively move to avoid predators, but epiphytic species are relatively less influenced by predation. Epiphytic cladoceran species are more sensitive to food availability than predation, and their distribution is related to food sources. For example, Sakuma et al. (2004) suggested that epiphytic chydorid cladocerans such as Alona migrated from the reed zone to the submerged macrophyte zone in summer and may select food-rich habitats and migrate seasonally. However, S. crystallina is vulnerable to fish predation and periods of high population density are often short (Nurminen et al. 2001; Balayla and Moss 2003). Nurminen et al. (2007) also reported that predation by fish has a strong effect on the migration of $S$. crystallina. They have relatively larger than other epiphytic cladocerans (Alona, Chydorus, and Pleuroxus) and thus can be easily captured by predators. However, the lack of response of S. crystallina to simulated predation may indicate adaption to long-term movement 
patterns, such as diurnal migration (vertical and horizontal migration; Zaret and Suffern 1976; Burks et al. 2002). Therefore, we conclude that $S$. crystallina was not influenced by fish chemical cues in the short term.

The stable isotope analysis indicated that S. crystallina are affected more by availability of EPOM on macrophyte stands than that of SPOM in the water. Their habit is to attach to aquatic macrophytes by means of the maxillary gland and thus filter feed from a fixed position (Fairchild 1981). Therefore, we suggest that S. crystallina consumes more EPOM than SPOM. Consumption of EPOM by $S$. crystallina plays an important role in the freshwater food web. Epiphytic materials on macrophyte stands are transported across food webs to epiphytic species such as $S$. crystallina (Schindler and Scheuerell 2002, Takai et al. 2002), and the trophic interactions can be interpreted as another route in food webs of freshwater ecosystems with developed macrophytes. Multiple trophic interactions can contribute not only to increased biodiversity in wetlands but also to sustaining an ecologically healthy food web.

In this study, we found that S. crystallina was more abundant in relatively less eutrophicated ecosystems where macrophytes were dominant. However, agricultural land surrounds most lentic freshwater ecosystems in South Korea, and non-point pollution sources continuously influence these ecosystems. Even though these ecosystems were frequently dominated by macrophytes, they had high nitrogen and phosphorus concentrations. Moreover, the development and growth of macrophytes is inhibited in some reservoirs due to their impermeable floors. We suggest that it is for these reasons that $S$. crystallina was not frequently observed in lentic freshwater ecosystems of South Korea. Diaphanosoma and Simocephalus have similar habitat requirements to $S$. crystallina, and they actively utilise macrophytes as habitat and refuges, resulting in greater abundances when macrophytes with complex structures, such as freefloating and submerged macrophytes, coexist (Lauridsen et al. 1996; Stansfield et al. 1997). S. crystallina was less dependent on such complexity and coexistence, but rather macrophyte biomass, water quality, and food availability. In addition, S. crystallina preferred emergent macrophytes that have relatively simple structures and thus is more vulnerable to predation by fish. Even though S. crystallina utilises emergent macrophytes as habitat, such plants did not play the role of refuges from fish predation. Moreover, S. crystallina did not show any avoidance behaviour to simulated fish presence. These habitat utilisation characteristics of S. crystallina may underlie its restricted distribution in lentic freshwater ecosystems of South Korea. Moreover, the species' preference for high water temperatures may make a significant contribution to their restricted distribution. Further investigation is needed to better understand the importance of macrophytes, fish predation, food availability, and water temperature in sustaining growth and development of S. crystallina populations.

\section{Conclusions}

S. crystallina was most frequently observed in shallow wetlands, and density was strongly associated with macrophyte biomass. Emergent macrophytes ( $P$. australis and $P$. distichum) were preferred by $S$. crystallina to other plant species. Although free-floating or submerged macrophytes make a large contribution to aquatic habitat complexity, because they are more easily agitated by wind and water currents, they were not suitable for attachment of S. crystallina. Empirical studies report that some epiphytic species utilise stem and leaves surfaces of free-floating macrophytes as habitat, but this is true of most small species (e.g. those belonging to Alona, Chydorus, and Pleuroxus). The space occupied by free-floating macrophytes in the water is relatively small; thus, it is difficult for the large $S$. crystallina to use free-floating macrophytes. They attach to stem and leaf surfaces of macrophytes by means of secreted glues from the nuchal organ. Therefore, S. crystallina can more firmly attach to macrophytes than other epiphytic cladoceran species. We found greater densities of S. crystallina as the shaking effort increased. However, attachment of $S$. crystallina to substrate surfaces was not affected by simulated predation. Some studies suggest that predation threats by fish have strong effects on S. crystallina, but S. crystallina did not immediately respond to such threats in this study. The results of stable isotope analysis showed that $S$. crystallina primarily utilises EPOM as its food source. $S$. crystallina consumed food source through filter feeding from a fixed position on macrophyte stands, attached by means of the maxillary gland. Consequently, S. crystallina abundance seems to be more strongly correlated with macrophyte biomass than other cladoceran species. This may contribute to this species' predominance in various freshwater ecosystems where macrophytes dominate.

\section{Acknowledgements \\ This research was fully supported by Basic Science Research Program through the National Research Foundation of Korea (NRF) funded by the Ministry of Education (grant number: NRF-2012-R1A6A3A04040793; http:// www.nrf.re.kr). The funders had no role in study design, data collection and analysis, decision to publish, or preparation of the manuscript.}

\section{Authors' contributions}

JYC carried out the field studies (collection and experiment), participated in the sequence alignment, and drafted the manuscript. KSJ participated in the design of the study and performed the statistical analysis. SKK and SHS participated in the sequence alignment. GJJ conceived of the study, participated in its design and coordination, and helped to draft the manuscript. All authors read and approved the final manuscript.

Competing interests

The authors declare that they have no competing interests. 


\section{Author details}

National Institute of Ecology, Seo-Cheon Gun, Chungcheongnam province 325-813, South Korea. ${ }^{2}$ Department of Biological Sciences, Pusan National University, Busan 609-735, South Korea. ${ }^{3}$ Institute of Environmental Technology and Industry, Pusan National University, Busan 609-735, South Korea. ${ }^{4}$ Nakdong River Environment Research Center, Goryeong-Gun, Gyeongsangbuk-do, South Korea.

\section{Received: 18 November 2015 Accepted: 24 June 2016}

\section{Published online: 24 October 2016}

\section{References}

Balayla, D. J., \& Moss, B. (2003). Spatial patterns and population dynamics of plant-associated microcrustacea (cladocera) in an English shallow lake (Little Mere, Cheshire). Aquatic Ecology, 37, 417-435.

Burkett, V., \& Kusler, J. (2000). Climate change: potential impacts and interactions in wetlands of the United States. Journal of the American Water Resources Association, 36, 313-320.

Burks, R., Lodge, D. M., Jeppesen, E., \& Lauridsen, T. L. (2002). Diel horizontal migration of zooplankton: costs and benefits of inhabiting littoral zones. Freshwater Biology, 47, 343-365.

Castilho-Noll, M. S. M., Câmara, C. F., Chicone, M. F., \& Shibata, E. H. (2010). Pelagic and littoral cladocerans (Crustacea, Anomopoda and Ctenopoda) from reservoirs of the Northwest of São Paulo State, Brazil. Biota Neotropica, 10, $21-30$.

Cattaneo, A., Galanti, G. G., Gentinetta, S., \& Romo, S. (1998). Epiphytic algae and macroinvertebrates on submerged and floating-leaved macrophytes in an Italian lake. Freshwater Biology, 39, 725-740.

Choi, J. Y., Jeong, K. S., La, G. H., Kim, H. W., Chang, K. H., \& Joo, G. J. (2011). Interannual variability of a zooplankton community: the importance of summer concentrated rainfall in a regulated river ecosystem. Journal of Ecology and Field Biologyl, 34, 49-58.

Choi, J. Y., Jeong, K. S., La, G. H., \& Joo, G. J. (2014). Effect of removal of freefloating macrophytes on zooplankton habitat in shallow wetland. Knowledge Management Aquatic Ecosystems, 414, 11.

Choi, J. Y., Jeong, K. S., La, G. H., Kim, S. K., \& Joo, G. J. (2014). Sustainment of epiphytic microinvertebrate assemblage in relation with different aquatic plant microhabitats in freshwater wetlands (South Korea). Journal of Limnology, 73, 197-202.

Choi, J. Y., Jeong, K. S., Kim, S. K., La, G. H., Chang, K. H., \& Joo, G. J. (2014). Role of macrophytes as microhabitats for zooplankton community in lentic freshwater ecosystems of South Korea. Ecology Information, 24, 177-185.

De Meester, L., \& Cousyn, C. (1997). The change in phototactic behaviour of a Daphnia magna clone in the presence of fish kairomones: the effect of exposure time. In Cladocera: the Biology of Model Organisms (pp. 169-175). Netherlands: Springer.

Denny, P. (1994). Biodiversity and wetlands. Wetland Ecology and Management, 3, $55-61$.

Downing, J. A., \& Peters, R. H. (1980). The effect of body size and food concentration on the in situ filtering rate of Sida crytallina. Limnology and Ocreanography, 25, 883-895

Fairchild, G. W. (1981). Movement and microdistribution of Sida crystallina and other littoral microcrustacea. Ecology, 62, 1341-1354.

Findlay, C. S. T., \& Bourdages, J. (2000). Response time of wetland biodiversity to road construction on adjacent lands. Conservation Biology, 14, 86-94.

Gyllström, M., Hansson, L. A., Jeppesen, E., Garcia-Criado, F., Gross, E., Irvine, K. Kairesalo, T., Kornijow, R., Miracle, M., Nykänen, M., Nõges, T., Romo, S. Stephen, D., Van Donk, E., \& Moss, B. (2005). The role of climate in shaping zooplankton communities of shallow lakes. Limnology and Ocreanography, 50, 2008-2021

Jeong, K. S., Kim, D. K., \& Joo, G. J. (2007). Delayed influence of dam storage and discharge on the determination of seasonal proliferations of Microcystis aeruginosa and Stephanodiscus hantzschii in a regulated river system of the lower Nakdong River (South Korea). Water Research, 41, 1269-1279.

Jeppesen, E., Lauridsen, T. L., Kairesalo, T., \& Perrow, M. R. (1998). Impact of submerged macrophytes on fish-zooplankton interactions in lakes. In The structuring role of submerged macrophytes in lakes (pp. 91-114). New York: Springer.

Korean Ministry of Environment. (2006). IInland wetlands investigation: Sandle Wetland, Hwapo Wetland, Jangcheok Wetland and Gumgang Wetland]. [Report in Korean] (p. 348). Seoul: Korean Ministry of Environment \& National Wetlands Center.

Kotov, A. A., \& Boikova, O. (1998). Comparative analysis of the late embryogenesis of Sida crystallina (O.F. Müller, 1776) and Diaphanosoma brachyurum (Lievin, 1848) (Crustacea: Branchiopoda: Ctenopoda). Hydrobiologia, 380, 103-125.

Kuczyńska-Kippen, N. M., \& Nagengast, B. (2006). The influence of the spatial structure of hydromacrophytes and differentiating habitat on the structure of rotifer and cladoceran communities. Hydrobiologia, 559, 203-212.

Lauridsen, T. L., \& Lodge, D. M. (1996). Avoidance by Daphnia magna of fish and macrophytes: chemical cues and predator-mediated use of macrophyte habitat. Limnology and Oceanography, 41, 794-798.

Lauridsen, T., Pedersen, L. J., Jeppesen, E., \& Sønergaard, M. (1996). The importance of macrophyte bed size for cladoceran composition and horizontal migration in a shallow lake. Journal of Plankton Research, 18, 22832294.

Meerhoff, M., Iglesias, C., De Mello, F. T., Clemente, J. M., Jensen, E., Lauridsen, T. L. , \& Jeppesen, E. (2007). Effects of habitat complexity on community structure and predator avoidance behaviour of littoral zooplankton in temperate versus subtropical shallow lakes. Freshwater Biology, 52, 1009-1021.

Minagawa, M., \& Wada, E. (1984). Stepwise enrichment of $\delta{ }^{15} \mathrm{~N}$ along food chains: further evidence and the relation between $\mathrm{d} 15 \mathrm{~N}$ and animal age. Geochem Cosmochim Acta, 48, 1135-1140.

Mizuno, T., \& Takahashi, E. (1991). An illustrated quide to freshwater zooplankton in japan. Tokyo: Tokai University Press.

Moss, B., Kornijow, R., \& Measey, G. (1998). The effect of nymphaeid (Nuphar lutea) density and predation by perch (Perca fluviatilis) on the zooplankton communities in a shallow lake. Freshwater Biology, 39, 689-697.

Nurminen, L., Horppila, J., \& Tallberg, P. (2001). Seasonal development of the cladoceran assemblage in a turbid lake: role of emergent macrophytes. Archiv für Hydrobiologie, 151, 127-1540.

Nurminen, L., Horppila, J., \& Pekcan-Hekim, Z. (2007). Effect of light and predator abundance on the habitat choice of plant-attached zooplankton. Freshwater Biology, 52, 539-548.

O'Hare, M. T., Baattrup-Pedersen, A., Nijboer, R., Szoszkiewicz, K., \& Ferreira, T. (2006). Macrophyte communities of European streams with altered physical habitat. Hydrobiology, 566, 197-210.

Phillips, D. L., \& Gregg, J. W. (2001). Uncertainty in source partitioning using stable isotopes. Oecologia, 127, 171-179.

Pinnegar, J. K., \& Polunin, N. V. C. (1999). Differential fractionation of $\delta^{13} \mathrm{C}$ and $\delta^{15} \mathrm{~N}$ among fish tissues: implications for the study of trophic interactions. Functional Ecology, 13, 225-231.

Sakuma, M., Hanazato, T., Nakazato, R., \& Haga, H. (2002). Methods for quantitative sampling of epiphytic microinvertebrates in lake vegetation. Limnology, 3, $115-119$.

Sakuma, M., Hanazato, T., Saji, A., \& Nakazato, R. (2004). Migration from plant to plant: an important factor controlling densities of the epiphytic cladoceran Alona (Chydoridae, Anomopoda) on lake vegetation. Limnology, 5, 17-23.

Schindler, D. E., \& Scheuerell, M. D. (2002). Habitat coupling in lake ecosystems. Oikos, 98, 177-189.

Smokorowski, K. E., \& Pratt, T. C. (2007). Effect of a change in physical structure and cover on fish and fish habitat in freshwater ecosystems - a review and meta-analysis. Environmental Review, 15, 15-41.

Son, M. W., \& Jeon, Y. G. (2002). Physical geographical characteristics of natural wetlands on the downstream reach of Nakdong River. Journal of the Korean Association of Geographic Information Studies, 9, 66-76.

Sooknah, R. D., \& Wilkie, A. C. (2004). Nutrient removal by floating aquatic macrophytes cultured in anaerobically digested flushed dairy manure wastewater. Ecological Engineering, 22, 27-42

Stansfield, J. H., Perrow, M. R., Tench, L. D., Jowitt, A. J., \& Taylor, A. A. (1997) Submerged macrophytes as refuges for grazing Cladocera against fish predation: observations on seasonal changes in relation to macrophyte cover and predation pressure. In Shallow Lakes' 95 (pp. 229-240). Netherlands: Springer.

Takai, N., Mishima, Y., Yorozu, A., \& Hoshika, A. (2002). Carbon sources for demersal fish in the western Seto Inland Sea, Japan, examined by $\delta^{13} \mathrm{C}$ and $\delta^{15} \mathrm{~N}$ analyses. Limnology and Oceanography, 47, 471-730.

Thomaz, S. M., Dibble, E. D., Evangelista, L. R., Higuti, J., \& Bini, L. M. (2008). Influence of aquatic macrophyte habitat complexity on invertebrate abundance and richness in tropical lagoons. Freshwater Biology, 53, 358-367.

Thorp, J., \& Covich, A. P. (2001). Ecology and classification of North Amirican invertebrates (2nd ed., p. 950). San Diego: Academic Press. 
Vermaat, J. E., Santamaria, L., \& Roos, P. J. (2000). Water flow across and sediment trapping in submerged macrophyte beds of contrasting growth form. Archives of Hydrobiology, 148, 549-562.

Vieira, L. C. G., Bini, L. M., Velho, L. F. M., \& Mazão, G. R. (2007). Influence of spatial complexity on the density and diversity of periphytic rotifers, microcrustaceans and testate amoebae. Fundamental and Applied Limnology, $170,77-85$

Wetzel, R. G., \& Likens, G. E. (2000). Limnological analyses. 429 pp, Springer-Vera lag New York. Berlin Heidelberg Spin springer.

Zaret, T. M., \& Suffern, J. S. (1976). Vertical migration in zooplankton as a predator avoidance mechanism. Limnology and Oceanography, 21, 804-813.

Submit your next manuscript to BioMed Central and we will help you at every step:

- We accept pre-submission inquiries

- Our selector tool helps you to find the most relevant journal

- We provide round the clock customer support

- Convenient online submission

- Thorough peer review

- Inclusion in PubMed and all major indexing services

- Maximum visibility for your research

Submit your manuscript at www.biomedcentral.com/submit
Biomed Central 